\title{
DOES THE WASTEWATER PRODUCED BY THE WATER STEAM DISTILLATION OF ROSE OIL FROM ROSA ALBA L. AND ROSA DAMASCENA MILL. HAVE GENOTOXIC POTENTIAL?
}

\author{
Svetla Gateva $^{1^{*}}$, Gabriele Jovtchev ${ }^{1}$, Tsveta Angelova ${ }^{1}$, Ana Dobreva ${ }^{2}$, Milka Mileva ${ }^{3}$ \\ ${ }^{1 *}$ Institute of Biodiversity and Ecosystem Research, Bulgarian Academy of Sciences, \\ 2 Gagarin Str., Sofia 1113, Bulgaria; \\ ${ }^{2}$ Institute for Roses and Aromatic Plants, 49 Osvobojdenie Blvd, Kazanlak 6100, Bulgaria; \\ ${ }^{3}$ The Stephan Angeloff Institute of Microbiology, Bulgarian Academy of Sciences, \\ 26 Acad. G. Bonchev Str., Sofia 1113, Bulgaria; \\ *Corresponding Author Svetla Gateva, e-mail: spetkova2002@yahoo.co.uk;
}

Received May 2021; Accepted June 2021; Published August 2021;

DOI: https://doi.org/10.31407/ijees11.402

\begin{abstract}
Bulgaria is known as one of the main producers of high quality rose oil from Rosa damascena Mill. and Rosa alba L., which are valued on the world market for fragrances with the rating "Royal Class". Wastewater is one of the wastes discarded in the environment as result of water steam distillation applied in rose oil production. There are scarce data whether this waste harms the soil or it can be recovered, and whether this waste could be utilized further. To address these questions, this study investigated the potential cytotoxic/genotoxic effect of wastewater produced by water steam distillation of oil from $R$. alba, and $R$. damascena. Five concentrations (from 3 to $20 \%$ ) of wastewater of both roses applied for $1 \mathrm{~h}$ and 4 hours were tested for genotoxicity by chromosome aberration assay in two test-systems, barley and lymphocyte cultures. Cytotoxicity was determined by mitotic index. Both wastewaters showed not high, but statistically significant genotoxic activity at the concentrations applied, as lymphocytes had higher sensitivity than barley cells. Clear dose-dependence was detected in lymphocytes treated with $R$. alba L. wastewater, whereas close values of aberrations for all concentrations was observed in barley. Genotoxic effect of prolonged treatment was lower than that of $1 \mathrm{~h}$ in both test-systems. Wastewater of $R$. damascena Mill. induced slightly higher genotoxicity compared with that of $R$. alba L. No concentration dependence was obtained in both test-systems neither for short-time treatment, nor for the longer $4 \mathrm{~h}$ period. Our data suggest that the wastewaters produced by the water steam distillation of oil from both roses are promising for further use in practice.
\end{abstract}

Keywords: wastewater, $R$. alba L. and $R$. damascena Mill., genotoxicity, test-systems 